\title{
JOURNAL.RU
}

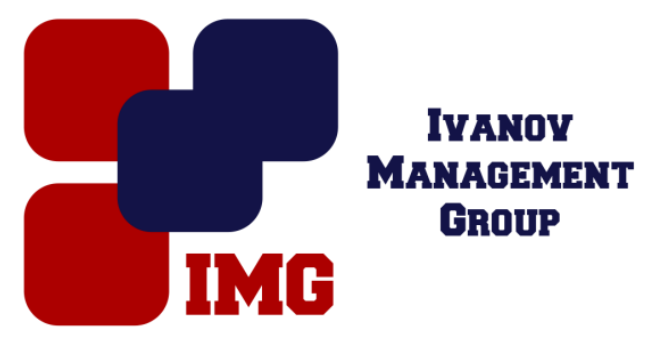

Никольская Е.Ю.

Российский Экономический Университет имени Г.В. Плеханова Москва, Россия

doi: 10.18411/lj-31-07-2017-03

idsp 000001:1j-31-07-2017-03

\section{Рекомендации по совершенствованию контрольно-измерительных материалов для оценки компетенций студентов,обучающихся по направлению «Туризм» и «Гостиничное дело»}

\section{Аннотация}

В статье рассматриваются проблемы формирования оценочных средств в высших учебных заведениях, проведен анализ проблем по разработке контрольно-измерительных материалов, предложены рекомендации по совершенствованию разработки оценочных средств и контрольноизмерительных материалов для оценки компетенций студентов, обучающихся по программам «Туризм» и «Гостиничное дело».

Ключевые слова: освоение компетенций, оценочные средства, контрольно-измерительные материалы, профессиональные стандарты, зарубежный опыт, рекомендации.

Приоритетными направлениями развития туризма в РФ являются - как создание инфраструктуры, повышение качества обслуживания туристов и эффективное продвижение туризма на внутреннем и внешнем рынках, так и совершенствование системы профессиональной подготовки кадров в соответствии с требованиями отраслевых профессиональных стандартов.

Гостиничный бизнес в настоящее время предъявляет высокие требования к содержанию учебных программ, технологиям обучения, организации учебного процесса и производственной практике в процессе подготовки бакалавров по Гостиничному делу. Серьезнее становятся требования к подбору и отбору кадров для работы в гостиничных предприятиях, в связи с постоянным 
развитием современных технологий и методов управления, маркетинговых концепций и международных стандартов обслуживания в гостиничной деятельности.

В ходе анализа анкет руководителей отраслевых предприятий были выявлены следующие требования работодателей к компетенциям выпускника бакалавра по гостиничному делу, наиболее важные для работы в гостиничных комплексах столицы (Табл. 1).

Требования к практическому опыту работы у выпускников на предприятиях гостиничного бизнеса указали $68 \%$ работодателей. Среди важных личностных качеств выпускников работодатели выделили следующие: обучаемость $-45 \%$, мотивация к профессиональному развитию $-65 \%$, осваивать смежные профессии и готовность работать в разных подразделениях в рамках одного предприятия - $70 \%$.

Таблица 1.

Наиболее значимые для работодателей компетениии выпускника по направлению 43.03.03 «Гостиничное дело»

\begin{tabular}{|c|c|c|}
\hline $\begin{array}{c}\text { Компетенция } \\
\text { в стандарте } \\
43.03 .03 \\
\end{array}$ & Характеристика & $\begin{array}{c}\text { Степень } \\
\text { значимости }\end{array}$ \\
\hline OK- 4 & $\begin{array}{lll}\text { знание } & \text { организационно-нормативных } & \text { документов, } \\
\text { регламентирующих гостиничную деятельность }\end{array}$ & $50 \%$ \\
\hline OK-5 & $\begin{array}{l}\text { способностью к коммуникации на русском и иностранном языках } \\
\text { для решения задач межличностного и } \\
\text { взаимодействия }\end{array}$ & $55 \%$ \\
\hline ОПК-1 & $\begin{array}{l}\text { способность к внедрению инноваций и работать в глобальных } \\
\text { компьютерных } \\
\text { безопасность }\end{array}$ & $65 \%$ \\
\hline ОПК-3 & $\begin{array}{l}\text { готовность применять нормативно-правовую и технологическую } \\
\text { документацию, регламентирующую гостиничную деятельность }\end{array}$ & $52 \%$ \\
\hline ПК-4 & $\begin{array}{l}\text { способность контролировать правильность технологических } \\
\text { процессов (технология бронирования, регистрации и выписки } \\
\text { гостя) }\end{array}$ & $70 \%$ \\
\hline ПК-5 & $\begin{array}{l}\text { способность находить организационно-управленческие решения в } \\
\text { нестандартных } \quad \text { ситуациях, готовность нести за них } \\
\text { ответственность, руководить людьми и подчиняться }\end{array}$ & $80 \%$ \\
\hline ПК-6 & $\begin{array}{l}\text { готовность анализировать результаты } \\
\text { функциональных подразделений гостиниц и средств размещения, } \\
\text { уровень обслуживания потребителей, делать соответствующие } \\
\text { выводы }\end{array}$ & $75 \%$ \\
\hline ПК-9 & \begin{tabular}{l}
\multicolumn{4}{l}{ способность к исследовательской деятельности по формированию } \\
и продвижению гостиничных продуктов в соответствии с \\
требованиями разных групп потребителей
\end{tabular} & $65 \%$ \\
\hline
\end{tabular}

Для бакалавров по направлению «Туризм» работодателями были выделены следующие общекультурные и профессиональные компетенции выпускников (Табл.2): 
Значимые требования работодателей к компетенциям выпускников по направлению 43.03.02 «Туризм»

\begin{tabular}{|c|c|c|}
\hline $\begin{array}{l}\text { Компетенцияв } \\
\text { стандарте } \\
43.03 .02\end{array}$ & Характеристика & $\begin{array}{c}\text { Степень } \\
\text { значимости }\end{array}$ \\
\hline OK-6 & $\begin{array}{c}\text { знание и соблюдение общеправовых основ с учетом } \\
\text { международного и российского права } \\
\end{array}$ & $56 \%$ \\
\hline OK-7 & $\begin{array}{c}\text { способность поддерживать должный уровень подготовленности } \\
\text { для обеспечения профессиональной деятельности }\end{array}$ & $52 \%$ \\
\hline $\mathrm{OK}-2$ & $\begin{array}{c}\text { способность использовать основы экономических знаний при } \\
\text { оценке эффективности результатов деятельности в различных } \\
\text { сферах }\end{array}$ & $66 \%$ \\
\hline ОПК-1 & $\begin{array}{c}\text { способностью решать стандартные задачи профессиональной } \\
\text { деятельности с применением информационно- } \\
\text { коммуникационных технологий и с учетом основных } \\
\text { требований информационной безопасности, организация } \\
\text { туристкой деятельности }\end{array}$ & $63 \%$ \\
\hline ОПК-3 & $\begin{array}{c}\text { способность организовать процесс обслуживания потребителей } \\
\text { и (или) туристов }\end{array}$ & $82 \%$ \\
\hline ПК-5 & $\begin{array}{c}\text { способность рассчитать и проанализировать затраты } \\
\text { деятельности предприятия туристской индустрии, туристского } \\
\text { продукта в соответствии с требованиями потребителя и (или) } \\
\text { туриста, обосновать управленческое решение }\end{array}$ & $76 \%$ \\
\hline ПК-6 & $\begin{array}{c}\text { анализировать и обрабатывать информацию о туристской } \\
\text { деятельности }\end{array}$ & $54 \%$ \\
\hline ПК-7 & $\begin{array}{c}\text { способность использовать методы мониторинга рынка } \\
\text { туристских услуг }\end{array}$ & $68 \%$ \\
\hline ПК-12 & $\begin{array}{c}\text { способностью использовать нормативные документы по } \\
\text { качеству, стандартизации и сертификации в туристской } \\
\text { индустрии }\end{array}$ & $65 \%$ \\
\hline ПК-13 & $\begin{array}{c}\text { способность к общению с потребителями туристского продукта, } \\
\text { обеспечению процесса обслуживания с учетом требований } \\
\text { потребителей и (или) туристов } \\
\end{array}$ & $72 \%$ \\
\hline
\end{tabular}

Анализ мнений работодателей к важности компетенций выпускников по направлениям 43.03.03 «Гостиничное дело» и 43.03.02 «Туризм» показал, что все они хотят видеть помимо теоретической подготовки выпускников, умения и практические навыки по организации и осуществлению практической деятельности на предприятиях сферы туризма и гостеприимства.

В условиях преобразования профильного образования требуется современная система контроля знаний и компетенций, способствующая достижению требований ФГОС ВО и эффективному освоению выпускниками ООП ВО, которая должна выстраиваться как комплексный процесс планирования, организации и проведения контрольно-оценочных процедур по заданному набору оцениваемых критериев. 
Анализ проблем формирования оценочных средств в профильных учебных заведениях, обучающих по направлению «Туризм» и «Гостиничное дело» позволил выявить ряд следующих существующих проблем:

- основной акцент на проверке знаний студентов;

- непонимание компетентностной модели обучения, отсутствие опыта по разработке матрицы компетенций и модели выпускника;

- отсутствует единая методология оценивания компетенций и результатов обучения студентов;

- практически отсутствуют навыки у преподавателей по разработке контрольно-измерительных материалов для оценивания компетенций студентов в рамках ФГОС ВО и применений технологий оценивания;

- непонимание взаимосвязи требований образовательных стандартов и профессиональных квалификаций, отсутствует системный подход к их обновлению с учётом профстандартов;

- необходимость совершенствования методической базы с учётом активных технологий обучения и новых методов оценивания его результатов;

- оценка компетенций студентов и квалификаций студентов не может осуществляться на основе традиционных средств и контрольноизмерительных материалов.

Исследование зарубежного опыта по оценке компетенций выпускников в профильных ВУЗах и международных университетах позволило выявить следующие преимущества: формирование базы контрольно- измерительных материалов, использование конструкторов тестов, к разработке практических компетентностных заданий привлекаются представители гостиничного и туристического бизнеса и академического сообщества; совместная обработка, шкалирование и интерпретация результатов освоения компетенций; мониторинг индивидуальных достижений студентов на протяжении всего периода обучения для каждого студента.

Таким образом, можно сделать вывод, что основными причинами недостатков в оценке компетенций студентов в профильных ВУЗах являются:

- диверсификация предметного содержания в ФГОС ВО; ограниченность дисциплинарного подхода при разработке 
контрольно-измерительных материалов для оценочной деятельности профессионального образования;

- дробность и повторяемость фрагментов компетенций по дисциплинам;

- - отсутствие учёта освоения компетенций каждого студентов в период всего обучения;

- междисциплинарного характер компетенций требует разработки комплексных компетентностно-ориентированных заданий;

- низкая мотивация преподавателей и отсутствие навыков по разработке контрольно-измерительных материалов и практических заданий.

На основе проведённого исследования и сделанных выводов можно дать следующие рекомендации:

- необходима подготовка и повышение квалификации преподавателей по адаптации образовательных и профессиональных стандартов в практику ООП разработке фондов оценочных средств и контрольноизмерительных материалов;

- требуется разработка современных контрольно-измерительных материалов для оценки компетенций студентов с учётом профессиональных стандартов;

- необходимо издание научно-методического обеспечения по оценке квалификаций, готовности студентов к профессиональной деятельности;

- создание федеральной базы контрольно-измерительных материалов и фонда оценочных средств;

- подготовка экспертов по сертификации и стандартизации;

- привлечение к разработке практических заданий представителей научного и профессионального сообщества;

- разработка показателей проявления компетенций студентов, методики оценки и учёта действий по решению типовых задач в условиях профессиональной деятельности;

- обеспечение независимости оценки для получения объективного оценивания компетенций студентов и выпускников по направлению «Туризм» и «Гостиничное дело». 
Всем профильным вузам необходимо обеспечить создание фонда оценочных средств и условия независимого оценивания уровня готовности студентов к профессиональной деятельности. В системе оценочных средств, ориентированных на компетентностный подход, важное место должна занимать методика разработки современных контрольно-измерительных материалов для оценки знаний и умений, необходимых для будущей профессиональной деятельности студентов, обучающихся по программам «Туризм» и «Гостиничное дело».

Основными функциями фонда оценочных средств являются: разработка и учет контрольно-измерительных материалов; стандартизация оценочных средств, обеспечение системности оценивания, формирование статистических отчетов, оперативное изменение контрольно-измерительных материалов после их апробации.

Фонд оценочных средств для проведения промежуточной аттестации студентов по направлению «Туризм» и «Гостиничное дело», входящий в состав рабочей программы дисциплины, должен включать:

- перечень компетенций с указанием этапов их формирования;

- описание показателей и критериев оценивания компетенций, описание шкал оценивания;

- методические материалы, определяющие процедуры оценивания знаний, умений, навыков и (или) опыта деятельности;

- типовые контрольные задания и материалы, необходимые для оценки знаний, умений, навыков и (или) опыта деятельности, характеризующие этапы формирования компетенций в процессе каждой образовательной программы.

Ключевые принципы создания фонда оценочных средств используемые для оценки компетенций студентов: валидность контрольно измерительных материалов; соответствие содержания материалов уровню и стадии обучения; четко сформулированные критерии оценки; максимально объективные процедуры и методы оценки; высококвалифицированные эксперты для оценки; четко прописанные рекомендации действий по итогам оценки.

Фонды оценоночных средств должны иметь следующую структуру: модели компетенций и программы их оценивания в соответствии с уровнями обучения студентов; совокупность контрольно-измерительных материалов (опросников, тестов, кейсов и др.); положения и инструкции определяющие процедуры оценивания, требования к экспертам и разработчикам, технологии 
обработки результатов оценивания компетенций, матрица соответствия компетенций, составных частей ООП, оценочных средств; методические рекомендации по разработке оценочных средств для проведения оценки компетенций студентов.

С помощью ФОС возможно осуществлять контроль за уровнем освоения студентами требуемых знаний, умений, навыков, определенных в образовательном стандарте «Туризм» и «Гостиничное дело»; определять в процессе изучения дисциплины положительные (или отрицательные) результаты студентов; обеспечить соответствия учебного процесса будущей профессиональной деятельности с помощью внедрения инновационных методов обучения в образовательный процесс.

Статья подготовлена в рамках гранта Российского экономического университета им. Г.В. Плеханова «Разработка и апробация механизма оценки квалификаций сотрудников индустрии гостеприимства и выпускников вузов на основе применения профессиональных стандартов».

1. Никольская Е.Ю. Методы оценки компетенций персонала в индустрии гостеприимства. Социально-экономические и правовые основы развития экономики: коллективная монография. - Уфа: Аэтерна, 2015

2. Титиевская Е.М., Никольская Е.Ю. Специфика формирования и оценки кадрового потенциала гостиничного предприятия. Вестник Самарского государственного экономического университета. 2016. № 7 (141). С. 106 - 111

3. Зайцева Н.А. Ильина Е.Л., Никольская Е.Ю. Романова М.М. Оценка профессиональных квалификаций сотрудников индустрии гостеприимства, - Москва: РУСАЙНС, 2016. - $254 \mathrm{c}$.

4. Зайцева Н.А.Ушанов Ю.В. Национальная система профессиональных квалификаций: организационно-методические основы создания: монография/Н.А. Зайцева, Ю.В. Ушанов. — М.: РУСАЙНС, 2016. - 184 с.

5. Zaitseva, N.A. The role of education system in adaptation of gra $\neg$ duates from Russian institutes and colleges at European enterprises (by ex $\neg$ ample of service companies). Middle East Journal of Scientific Research 2013, Volume 13 Number (5), pp. 693 - 697

6. Zaitseva N.A., Ilina E.L., Nikolskaya E.Y., Romanova M.M., Larionova A.A.THE MAIN STRATEGIC DIRECTIONS OF THE EDUCATION SYSTEM DEVELOPMENT (ON THE EXAMPLE OF HIGHER EDUCATION INSTITUTIONS ON PERSONNEL EDUCATION FOR THE HOSPITALITY INDUSTRY)International Journal of Environmental and Science Education. 2016. T. 11. № 16.C. 9155-9168. 